Fourth International Conference on Sustainable Construction Materials and Technologies http://www.claisse.info/Proceedings.htm

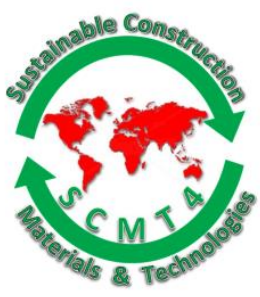

SCMT4

Las Vegas, USA, August 7-11, 2016

\title{
Experimental Study of the Effect of the Thermal Conductivity of EAF Slag Aggregates Used in Asphaltic Concrete of Wearing Courses on the Durability of Road Pavements
}

\author{
Marilda Barra' ${ }^{1 a}$, Diego Aponte ${ }^{1 b}$, Enric Vazquez ${ }^{2 a *}$, Braulio Mendez ${ }^{1 c}$, \\ Rodrigo Miro ${ }^{1 \mathrm{~d}}$, and Susanna Valls ${ }^{1 \mathrm{e}}$ \\ ${ }^{1}$ Universitat Politecnica de Catalunya, c/Jordi Girona 3, Campus Nord, Building B1, C.P. 08034 \\ Barcelona, Spain. \\ ${ }^{2}$ Constructing Cycle S.L., c/Jordi Girona 29, Edificio Nexus II, C.P. 08034 Barcelona, Spain. \\ Corresponding author, Email: <enric.vazquez@constructing-cycle.com>.
}

\begin{abstract}
Electric Arc Furnace (EAF) steel slag is the basic material used to obtain good quality aggregates in different layers of road pavements. Many scientific papers have reported on the high frictional and abrasion resistance of this material. EAF slag aggregates are hard, dense, chemically stable and have good adhesion with bitumen, all characteristics related with its high alkaline character. These properties are important in hot mix asphalt for wearing courses where high wear is present and optimal skid resistance is required. In some EAF slags, calcium and specially magnesium oxides are not completely combined, and upon contact with moisture convert into the corresponding hydroxides that could lead to volume changes. Only EAF slags with less than 3,5\% expansion are used in Europe as aggregates for asphalt concrete or hot mix asphalt.
\end{abstract}

In this paper, we present the experimental results of a study evaluating the consequences of the lower thermal conductivity of the EAF slag aggregates used in Catalonia (Spain). These aggregates have the necessary mechanical and chemical properties, as well as a very low expansion $(0,5$ to $1,5 \%)$. The EAF slag aggregates have a lower thermal conductivity $(0,85-1,20 \mathrm{~W} / \mathrm{mK})$ than natural aggregates, such as granite that are used in wearing courses $(1,60-1,80 \mathrm{~W} / \mathrm{mK})$. This property of the EAF slag aggregates can represent up to $30 \%$ less conductivity in asphalt concrete or hot mix asphalt. The different levels of depth in the wearing course with slag aggregates will be at lower temperature. This is especially important during the spring, summer and early fall months in the interior territories of the Mediterranean Coast, when due to the high temperatures the modulus of the mix in the wearing course is lower. The layer containing EAF slag is stiffer and the pavement has a better ability to resist the tendency to develop ruts and deformations. 


\section{INTRODUCTION}

This study is a part of the research project "Use of slags in asphalt concrete" promoted and financed by Abertis Autopistas España with the objective of increasing the use of steel slag as an economically and environmentally sustainable alternative material for building highways, and improving the skid resistance on highly stressed roads and repair.

EAF steel slag is a by-product obtained in the production of steel. ASTM [WK46376 2014] defines it as "a non-metallic by-product, consisting of essentially calcium silicates and ferrites combined with fused oxides of iron, aluminium, manganese, calcium and magnesium, that is developed simultaneously with steel in electric arc furnaces".

It is black in color, but after ageing in contact with the air and humidity, some white stains of $\mathrm{CaCO}_{3}$ and $\mathrm{MgCO}_{3}$ appear. In some EAF slags, calcium and specially magnesium oxides are not completely combined and upon contact with moisture, during the use as aggregates in the mix, the resulting its corresponding hydroxides can cause dangerous retarded volume changes. However, after a sufficiently long ageing process, the hydroxides react with $\mathrm{CO} 2$ and water from the environment, forming the corresponding carbonates that stabilize the slag. Only EAF slags with less of 3,5\% expansion [UNE EN 1744-1 2001] are used in Europe as aggregate for asphalt concrete or any class of hot mix asphalt.

EAF stable slags are hard, dense and can develop high alkalinity. Leachate of such slags typically shows a $\mathrm{pH}$ higher than 10, favoring the adhesion to bitumen, which has a slightly acidic $\mathrm{pH}$. These properties are important in hot mix asphalt, especially when slags are used as aggregates in wearing courses where high wear is present and good skid resistance is needed. The aggregates obtained by crushing of the slag have good angularity and have a high shear resistance. Aggregate represents $90 \%$ of the hot mix asphalt and the properties of the aggregate will have an important influence on the mechanical and chemical properties of the asphalt layer. Thereby, Asi et al [2007], reported that the mechanical properties of the mix improved significantly by replacing $75 \%$ of a limestone coarse aggregate by EAF aggregates.

Motz and Geisler [2001] compared the laboratory and road results of several tests on asphalt mixes with granite or EAF coarse aggregate and summarized the experiences. The researchers concluded that the resistance to polishing and the long-term stability of the surfaces remained high, and were generally higher in the layers with EAF slag, or in the worst case, equivalent to those seen in mixes with granite. Many other scientist and engineers have published papers about the influence of EAF slag aggregates on the properties of asphaltic wearing course, demonstrating that these aggregates are a high quality component for hot mix asphalt. From the environmental point of view, the use of EAF slag as road surface material saves existing resources of natural aggregates, produces benefits to the steel industry as well as the road operators, and saves land that would normally be used to dump waste.

Merkel,T. et al. [2000] studied, in the laboratory and on the road, the properties of several EAF aggregates and the resulting asphaltic mixtures. In one of the experimental road sections temperature was measured at different depths to compare the thermal behavior of the asphalt layers with conventional and EAF slag aggregates. The section of the road consisted of one $4 \mathrm{~cm}$ wearing course with open $0 / 8 \mathrm{~mm}$ asphalt, using EAF coarse aggregate in one case and conventional coarse aggregate in the other. The temperature was measured at 2,12 and $24 \mathrm{~cm}$ depth. The conclusion was that in the spring and in the summer, the section with the surface layer containing EAF aggregate reached lower temperatures at all the depth points 
measured compared to the layers containing conventional aggregates. These results suggest a potentially important influence of the presence of EAF slag aggregates on the deformation behaviour of pavement.

\section{MATERIALS AND EXPERIMENTAL SETUP}

The study was divided into three phases: (i) the first describing the chemical, mineralogical and physicomechanical characterization of different aggregates, (ii) the second summarizing mix design and mixes fabrication, and (iii) the third evaluating the behavior (mechanical and thermal) of the two mixes made.

\section{Materials}

This study included one type of granite aggregate (coarse fraction), one type of limestone aggregate (as fine and filler fraction), and one type of steel slag (as a substitute for the coarse fraction of granite). Granite and limestone aggregates were obtained from a mine close to Barcelona. The steel slag aggregates were obtained from Adec Global valorization company.

The physico-mechanical properties of aggregates are summarized in Table 1 and Figure 1 shows the size distribution (UNE EN 933-1, UNE EN 1097-2, UNE EN 1097-6)

Table 1. Physico-mechanicall properties of aggregates

\begin{tabular}{|c|c|c|c|c|c|}
\hline Property & Granite & Steel slag & Sand & Filler & Bitumen \\
\hline Density (g/cm3) & 2.60 & 3.50 & 2.58 & 2.55 & 1.00 \\
\hline Absorption (\%) & 0.58 & 1.85 & 1.40 & --- & --- \\
\hline
\end{tabular}

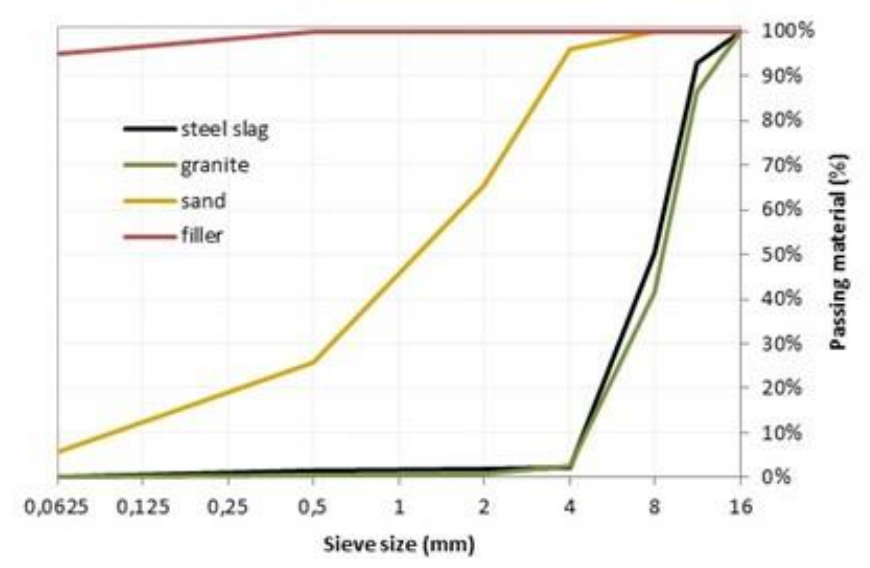

Figure 1. Size distribution of aggregates

The mineralogical composition of steel slag aggregate is: wuestite, magnetite, gehelenite, lime, portlandite and brucite, and calcium silicates. Table 2 shows the chemical composition of steel slag used in this research.

In Spain, the technical specification for roads (PG3-2008) requests the slag expansion test [UNE EN 1744$1]$ as a requirement for use on roads. The results are shown in Figure 2.

The granulometric composition in this work has been chosen based on Spanish technical specification [PG3-2008] that allows the use of discontinuous mixes for heavy traffic surface coarse. Figure 3 shows the gradations limits for BBTM11A mixes and the blend aggregates for asphalt mix with granite and steel slag. 
Table 2. Steel slag chemical composition

\begin{tabular}{|c|c|}
\hline Element & Quantity (\%) \\
\hline $\mathrm{MgO}$ & 2.76 \\
\hline $\mathrm{AL}_{2} \mathrm{O}_{3}$ & 8.27 \\
\hline $\mathrm{SiO}_{2}$ & 11.65 \\
\hline $\mathrm{P}_{2} \mathrm{O}_{5}$ & 0.38 \\
\hline $\mathrm{SO}_{3}$ & 0.68 \\
\hline $\mathrm{CaO}$ & 21.68 \\
\hline $\mathrm{TiO}_{2}$ & 0.62 \\
\hline $\mathrm{Cr}_{2} \mathrm{O}_{3}$ & 1.89 \\
\hline $\mathrm{MnO}_{2}$ & 4.60 \\
\hline $\mathrm{Fe}_{2} \mathrm{O}_{3}$ & 39.99 \\
\hline $\mathrm{ZrO}$ & 0.03 \\
\hline $\mathrm{LOI}$ & 0.00 \\
\hline
\end{tabular}

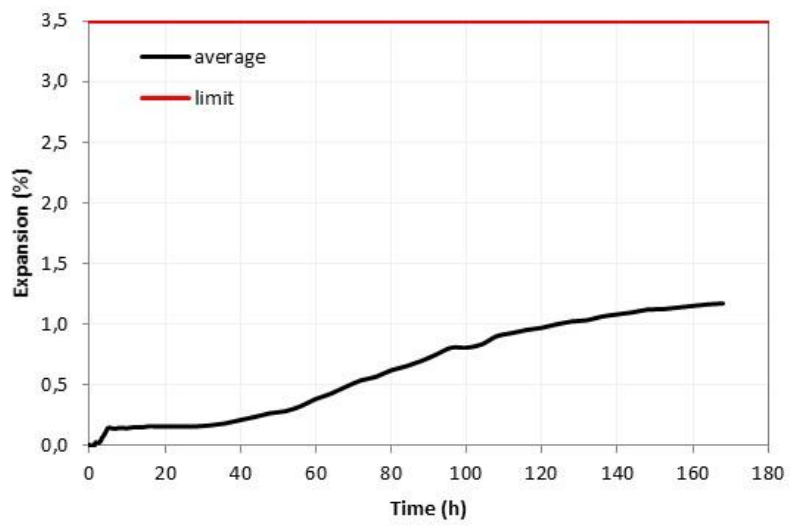

Figure 2. Expansion behavior of steel slag aggregate

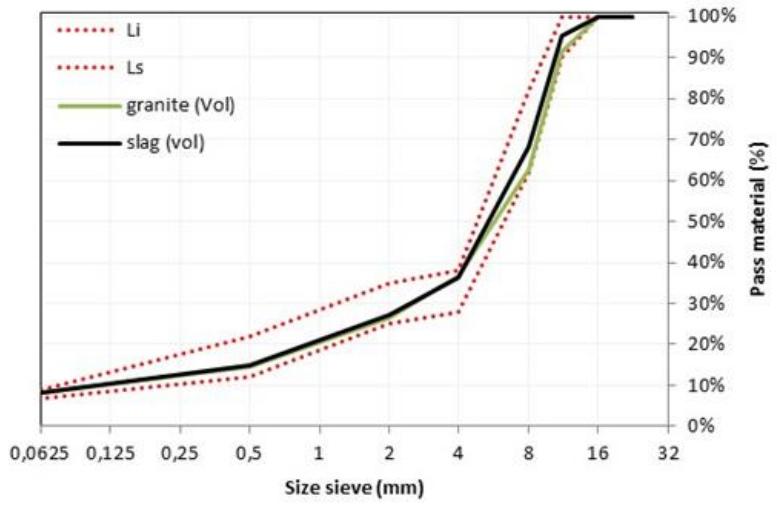

Figure 3. Aggregates mixture and limits for BBTM11A mixes

(volume \%)

Modified bitumen (BM3C) is used for making the mixtures with granite and steel slag aggregates. The use of modified bitumen is mandatory in asphaltic wearing courses of roads with heavy traffic in Spain. The dosage of each mixture is presented in the Table 3.

Table 3. Dosage of asphalt mixes

\begin{tabular}{|c|c|c|}
\hline \multirow{2}{*}{ Material } & \multicolumn{2}{|c|}{ Quantity (\% weight) } \\
\cline { 2 - 3 } & Granite & Steel slag \\
\hline Granite & 60.5 & --- \\
\hline Steel slag & --- & 67.5 \\
\hline Sand & 27.9 & 22.9 \\
\hline Filler & 6.1 & 5.1 \\
\hline Bitumen & 5.5 & 4.5 \\
\hline Total & 100.0 & 100.0 \\
\hline
\end{tabular}


Mixtures were prepared in the laboratory in accordance with standard impact method [UNE EN 12697-30]. For preparation of mix specimens, the aggregates were heated in an oven for $6 \mathrm{~h}$ at the temperature of 165 ${ }^{\circ} \mathrm{C}$, and then the heated bitumen $\left(160^{\circ} \mathrm{C}\right)$ was added into the aggregates. Subsequently, the material was mixed, and finally filler was added. It must be clarified that replacing the coarse aggregate fraction of the mixtures by steel slag results in changes in volume but this was corrected by density of different aggregates.

Fifteen identical samples were produce for each mix, and the compaction method was 50 hits per side with a Marshall hammer [UNE EN 12697-30]. Samples were tested for resilient modulus at 20, 30 and $40{ }^{\circ} \mathrm{C}$ [UNE EN 12697-26], indirect tensile strength [UNE EN 12697-23], moisture sensitivity [UNE EN 1269712], irradiation and thermal conductivity.

\section{Set up of thermal measurement (irradiation test)}

Thermal radiation test was performed on cylindrical samples of $102 \mathrm{~mm}$ in diameter and $60 \mathrm{~mm}$ height. Thermocouples were installed at the top $(0 \mathrm{~mm})$, middle $(30 \mathrm{~mm})$ and bottom $(60 \mathrm{~mm})$ of the cylindrical samples, for temperature change measurements. The temperature increases were generated by infrared light bulbs, which simulated the heat generated by the sun in warmer months. The test setup is shown in Figure 4.

Finally, the thermal conductivity was measured by a non-steady state procedure. In this study a sensor that rests on a face of the specimen was used and the device applied a constant current heat source to the sample. The sample was heated during the test, and it absorbed part of the heat depending on its thermal conductivity, while other part of heat caused a temperature rise at the sensor interface. The thermal conductivity was measured.

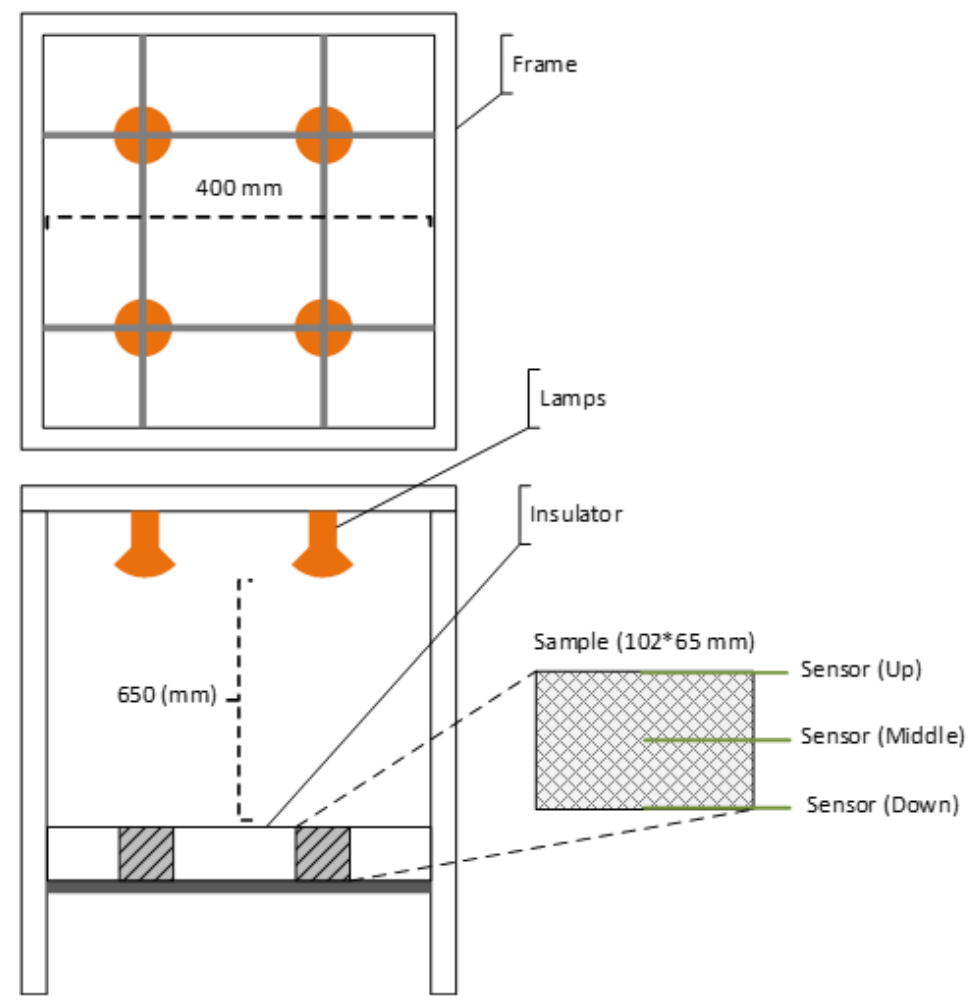

Figure 4. Radiation test setup 


\section{RESULTS AND DISCUSSIONS}

In Spain, the technical specification for road [PG3-2008] suggests that discontinuous mixes have a percentage of voids that is higher than 4\% [UNE EN 12697-8], and moisture susceptibility greater than 90\%. As shown in Figure 5 and Figure 6, these requirements were met.

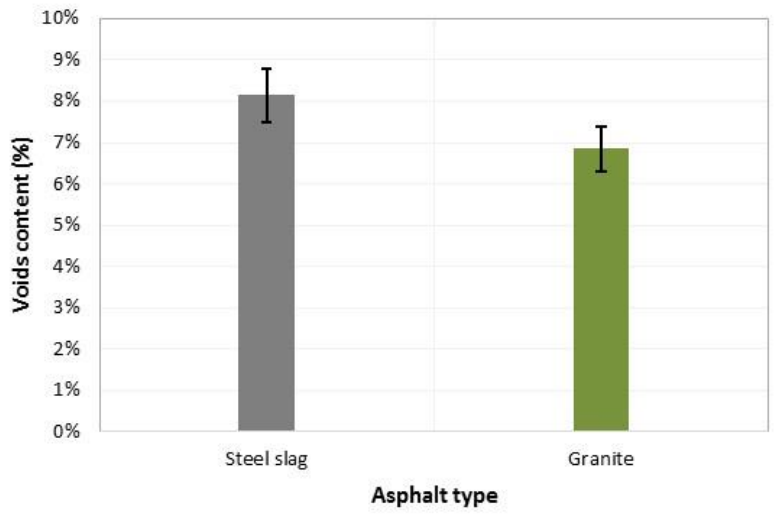

Figure 5. Asphalt mixes voids content

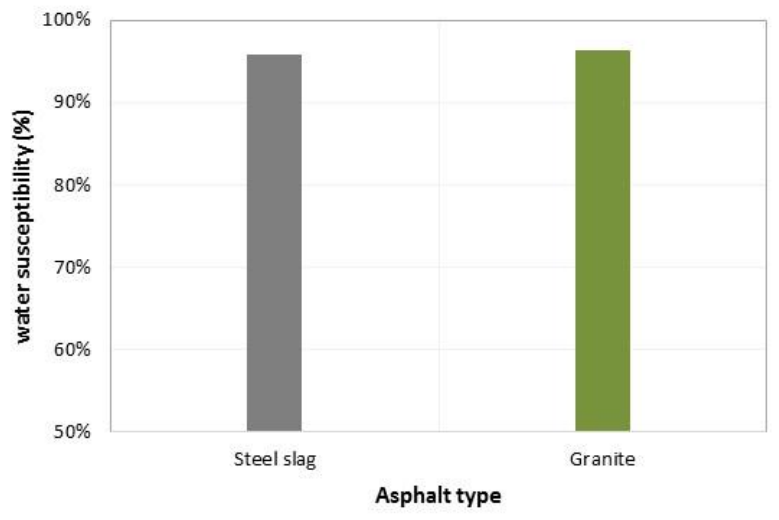

Figure 6. Asphalt mixes water susceptibility

Figure 7 shows the density of mixes [UNE EN 12697-8], obtaining higher values in the mix with steel slag, due to its higher density compared to granite density.

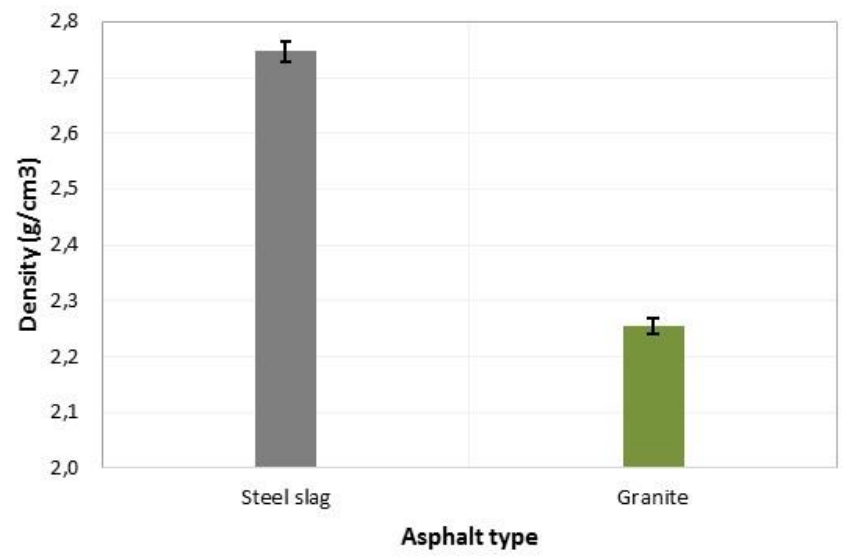

Figure 7. Asphalt mixes density

\section{Resilient modulus at different temperatures}

Resilient modulus is the most important parameter used in the mechanistic design of pavement structures. It is the measure of pavement response in terms of dynamic stresses and corresponding strains. Three specimens for each mixture were tested at 20,30 and $40{ }^{\circ} \mathrm{C}$, and the specimens were conditioned 4 hours at the respective test temperatures. Resilient modulus values for mixtures are presented in Figure 8. It indicates that mixtures containing steel slag have higher resilient modulus than mixtures contained granite. 


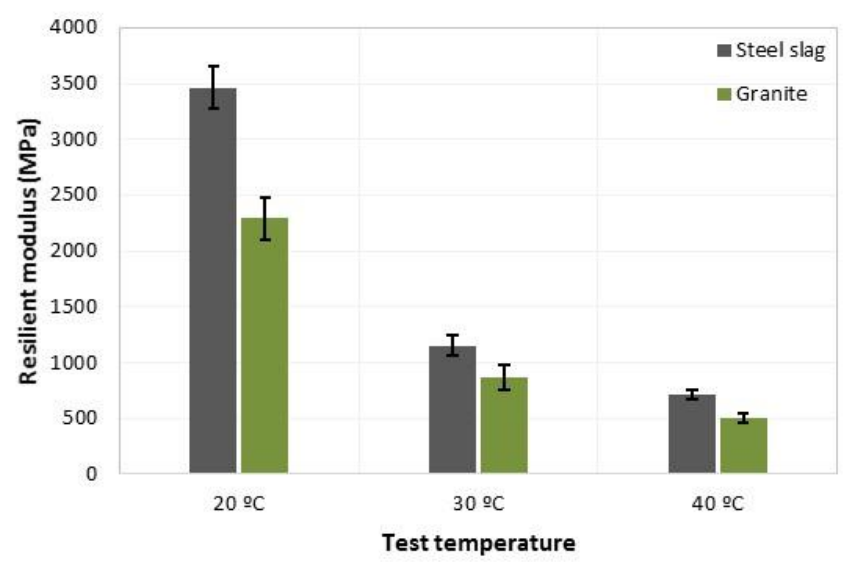

Figure 8. Asphalt mixes resilient modulus at different temperatures

Considering the resilient modulus results, mix with steel slag aggregates in their coarse portion showed the best performance. Replacing coarse portions of granite aggregate with steel slag resulted in an increase in resilient modulus of $34 \%, 25 \%$ and $29 \%$ at 20,30 and $40{ }^{\circ} \mathrm{C}$, respectively. This can most likely be attributed to the chemical bond between steel slag and bitumen and to the roughness of steel slag aggregates, giving the mix higher resilience properties. Consequently, a higher stiffness of the material at different temperatures contributes favorably to a better structural function of the flexible pavement.

\section{Indirect tensile strength at different temperatures}

The values of the indirect tensile strength at different temperatures of the two mixes obtained in this study are shown in Figure 9. Samples of each mixture were prepared at 20, 30 or $40{ }^{\circ} \mathrm{C}$, and the three samples were conditioned 4 hours at each respective test temperature.

It can be seen that all of the mixtures containing steel slag aggregates have higher values of indirect tensile strength under loading at $20^{\circ} \mathrm{C}$. The indirect tensile strength of mixtures containing granite are $9 \%$ lower at $20^{\circ} \mathrm{C}$. At $30^{\circ} \mathrm{C}$ and $40^{\circ} \mathrm{C}$ the values of ITR are similar for both mixes, however always slightly higher in mixtures with steel slag. This is due to the better adhesion of steel slag to binder than granite, which results from the chemical composition of the aggregates (higher $\mathrm{CaO}$ value for steel slag).

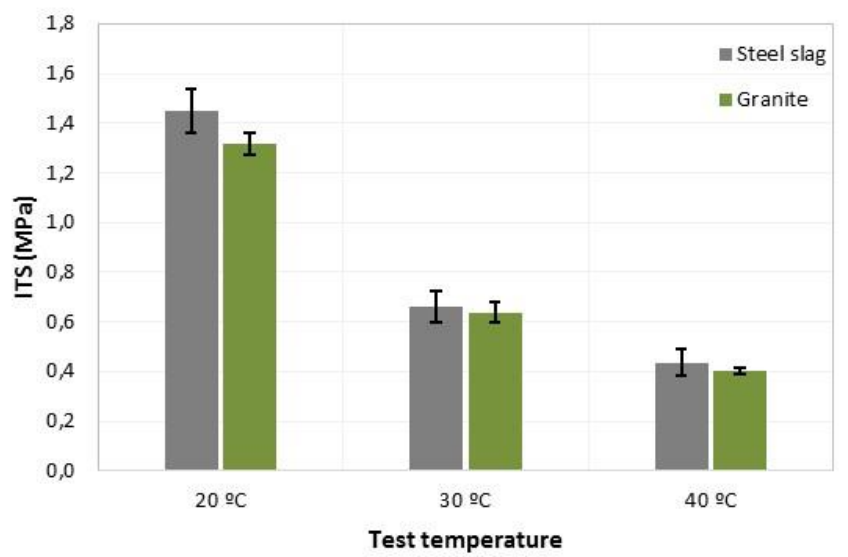

Figure 9. Indirect tensile strength of mixes at different temperatures 


\section{Radiation test and thermal conductivity}

The purpose of heat radiation in asphalt mixtures is to determine the behavior of the temperature change with increasing depth. This behavior will have an impact on the performance of the asphalt mixture, as is seen in the results above (modulus and ITS). The results obtained are shown in Figure 10 and Figure 11.

As seen in Figure 10, the steel slag asphalt mix shows lower temperature values than the mix with granite at all depths. In the mix with slag there is a difference of about $11^{\circ} \mathrm{C}$ (top $0 \mathrm{~mm}$ to bottom $60 \mathrm{~mm}$ ), while in mix with granite the difference is $7^{\circ} \mathrm{C}$.

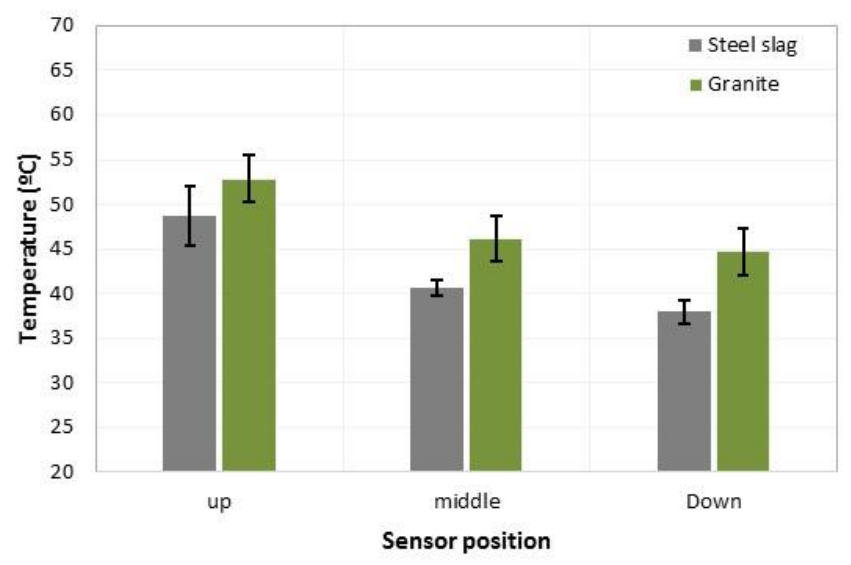

Figure 10. Temperature at different heights in specimens. Two hours of radiation

When mixtures were radiated for a period of 5 hours, the behavior was similar to that shown in Figure 10. At all depths, the temperature of steel slag mix was lower than the temperature of the mixture with granite.

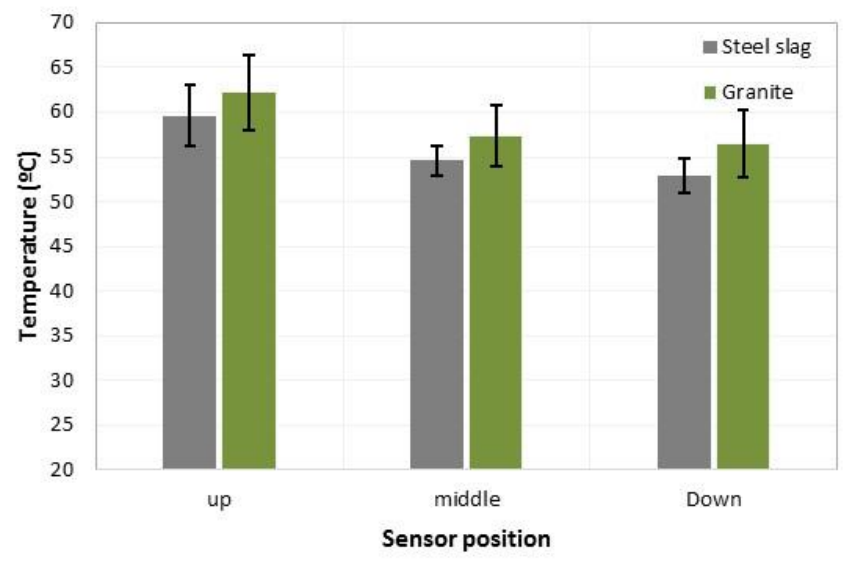

Figure 11. Temperature at different heights in specimens. five hours of radiation

In relation to the thermal conductivity, it can be seen that steel slag mixture has a lower conductivity, $44 \%$ less, compared to the mix with granite (Figure 11). This may be due to the porous internal structure of the slag particles. This structure is probably generated by bubbling oxygen in the steelmaking process. 


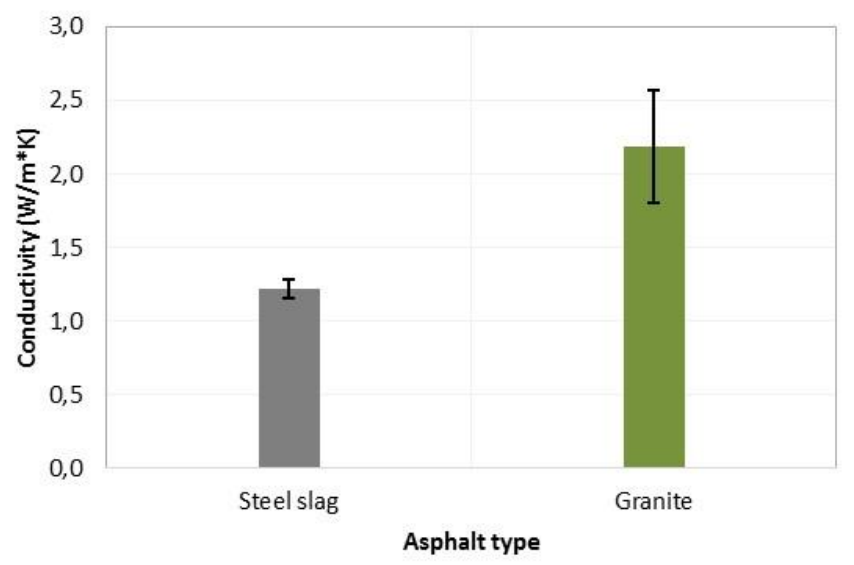

Figure 12. Thermal conductivity $(\mathrm{W} / \mathbf{m} * \mathbf{K})$.

\section{CONCLUSION}

On the basis of the results obtained in this research study, the following conclusions can be drawn:

- The results are satisfactory for mixes designed with granite and steel slag, fulfilling the requirements of the Spanish technical specifications for road (PG3-2008) in terms of fragmentation test (L.A.), voids content and water susceptibility.

- The resilient modulus results indicate that the steel slag mixture has a higher value compared to the granite aggregate mixture. Furthermore, temperature also influences the resilient modulus results.

- For the indirect tensile strength, steel slag mix shows higher values than granite aggregates at 20 ${ }^{\circ} \mathrm{C}$. The reason for this can be attributed to the interlocking properties of steel slag that impart greater adhesion to the mixture.

- The irradiation test indicates that steel slag mix has a lower thermal conduction compared to granite mix. This is confirmed by the thermal conductivity test.

The results of this study will help increase the use of EAF slag. In Spain, most of steel slag (>75\%) is stockpiled or dumped. Granite and porphyry are the only kind of rocks present in Catalonia that can be used in wearing courses. The utilization of Steel slag can save the use of this natural material and at the same time could reduce damage by permanent deformation in highway construction and increase road durability.

\section{ACKNOWLEDGEMENTS}

The authors thank Abertis responsables of the project Xavier Perucho, Josep Maria Escorsa, Santiago Rodón, as well to Adec Global and Firtec companies for materials provided for the realization of this research.

\section{REFERENCES}

Asi, Ibrahim., Qasrawi, Hisham., Shalabi, Faisal. (2007). "Use of steel slag aggregate in asphalt concrete mixes". Canadian journal of civil engineering, 34(8), 902-911. 
ASTM Standard WK46376 (2014). "Specification for blast furnace and steel furnace slag as produce during the manufacture of iron and steel". ASTM International, WestConshohocken, PA.

AENOR. UNE EN 933-1 (2012). "Tests for geometrical properties of aggregates - Part 1: Determination of particle size distribution - Sieving method".

AENOR. UNE EN 1097-2 (2006). "Tests for mechanical and physical properties of aggregates - Part 2: Methods for the determination of resistance to fragmentation".

AENOR. UNE EN 1097-6 (2006). "Tests for mechanical and physical properties of aggregates - Part 6: Determination of particle density and water absorption".

AENOR. UNE EN 1744-1 (2010). "Tests for chemical properties of aggregates - Part 1: Chemical analysis".

AENOR. UNE EN 12697-8 (2003). "Bituminous mixtures - Test methods for hot mix asphalt - Part 8: Determination of void characteristics of bituminous specimens".

AENOR. UNE EN 12697-12 (2009). 2Bituminous mixtures - Test methods for hot mix asphalt - Part 12: Determination of the water sensitivity of bituminous specimens".

AENOR. UNE EN 12697-23 (2004). "Bituminous mixtures - Test methods for hot mix asphalt - Part 23: Determination of the indirect tensile strength of bituminous specimens".

AENOR. UNE EN 12697-26 (2012). "Bituminous mixtures - Test methods for hot mix asphalt - Part 26: Stiffness".

AENOR. UNE EN 12697-30 (2013). "Bituminous mixtures - Test methods for hot mix asphalt - Part 30: Specimen preparation by impact compactor".

Merkel, T., Discher, H. P., Freund, H. J., Grossman, A., Motz, H. (2000) "Praktishe Erfahrungen mit Elektroofenschlacken im Strassenbau." Strasse und Autobahn, 51.

Ministry of infrastructure. (2008) "General technical specification for road and bridge Works, PG3.

Motz, H, Geisler, J. (2001). "Products of steel slags an opportunity to save natural resources." Waste Management 21, p.285-293. 